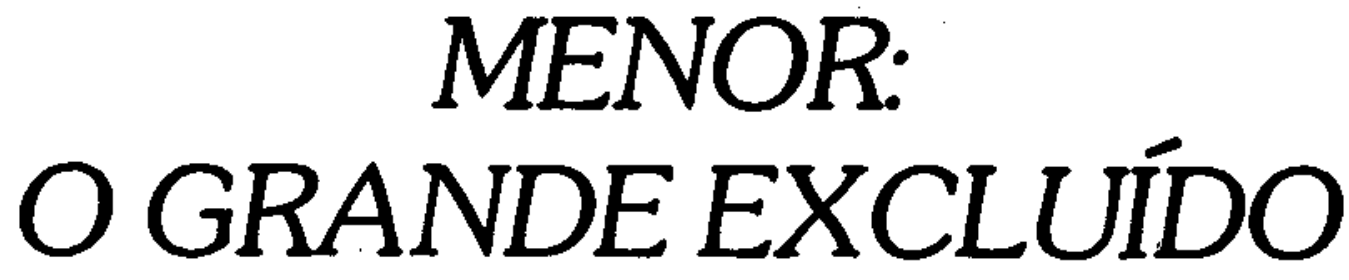

\title{
Marlene Guirado
}

Professora do Instituto de Psicologia da Universidade de São Paulo e atual presidente do CRP.06

A palavra Menor tem lugar e sentido no discurso social, quer seja ele jurídico, popular, administrativo, científico, intelectual ou poético.

$\mathrm{Na}$ linguagem jurídica, Menor é aquele que, nāo tendo ainda completado 18 ou 21 anos de ida. de, é considerado incapacitado para determinados atos sociais.

$\mathrm{Na}$ linguagem comum, por sua vez, este termo se particulariza, referindo-se à pobreza, ao aban. dono, ao cuidado assistencial e à infraçāo. Representa a criança que, proveniente de familia de nível socioeconômico baixo, vive em situação de abandono, marginalidade e/ou sob cuidado dos serviços públicos. Uma faixa etária, uma condição econômica e social e uma conduta delinquente atribuem sentido a esta palavra. Nảo é qualquer criança que é referida como menor: "E uma determinada criança que recebe este cognome, que veste esta identida. de. Parece que, no interior das re. laçoes entre os diferentes grupos e classes de uma sociedade, faz-se num acordo surdo, a circunscrição de uma "infáncia menor", que, em última instância, é percebida - e acaba por se constituir . como uma ameaça à sobrevivên. cia física e simbólica dos que năo săo Menores.
A mesma concepção se traduz na linguagem das instituiçóes de Assistência e Promoção Social, de Secretarias, Ministérios e entidades caritativas. A criança é, nos órgãos oficiais, invariavelmente, um Menor. E, como Menor, é definida "carente", "abandonada" ou "infratora". E a parcela da populaçāo ora considerada vítima afetiva e socialmente carente, ora considerada culpada por se mostrar um renitente e teimoso empecilho ao bom andamento da instituição que a "atende". E culpada por ser uma vítima que é rebelde, não se submete à rotina das casas em que se encontra, não assimila os beneficios e cuidados que the sāo oferecidos, enfim, nāo respon. de, como se esperaria que o fizesse, à "ajuda que recebe".

Abrindo outro feixe de significados para o termo Menor, estão aqueles que, da posição de pesquisadores e estudiosos de questós sociais, procuram resgatar as relaçōes fundantes: resgatam $o$ interjogo da dominaçáo econômica, social, ideológica e, sempre institucional, que engendra a existência concreta de uma parte da infância em condiçăo de abandono bem como as representaçōes sociais dessa existência.

O Menor é, ainda, "cantado em prosa e verso". Na música e na poesia ele é o Guri e o Pivete: um personagem ambíguo, que funde necessidade de sobrevivência e violência, quer na posiçăo de quem ataca, quer na posiçāo de quem é atacado; mas, inegavelmente, um personagem que desperta simpatia e afeto.

São, portanto, muitos os discursos sobre o Menor. Fala-se sobre ele e dele.

Entre afirmaçōes sobre a ameaça e o perigo que representa, e afirmaçóes sobre sua condição de representante de uma determinada ordem social, a criança em abandono - o Menor - é sempre lembrada, referida, mencionada. Ela tem um lugar no pensamento social, quer seja ele alienado/justificador, quer seja ele critico questionador, quer seja ele poético.

Esse lugar, entretanto, é, via de regra, o lugar do referido, do relatado, do anunciado/denunciado, do mencionado. Năo costuma ser o lugar de quem refere, relata, anuncia/denuncia, menciona. É o lugar de objeto, năo de su. jeito, no discurso.

E claro que há uma diferença conforme o que se fala. Um discurso que se pretende crítico, porque explicita contradiçăo no fazer 


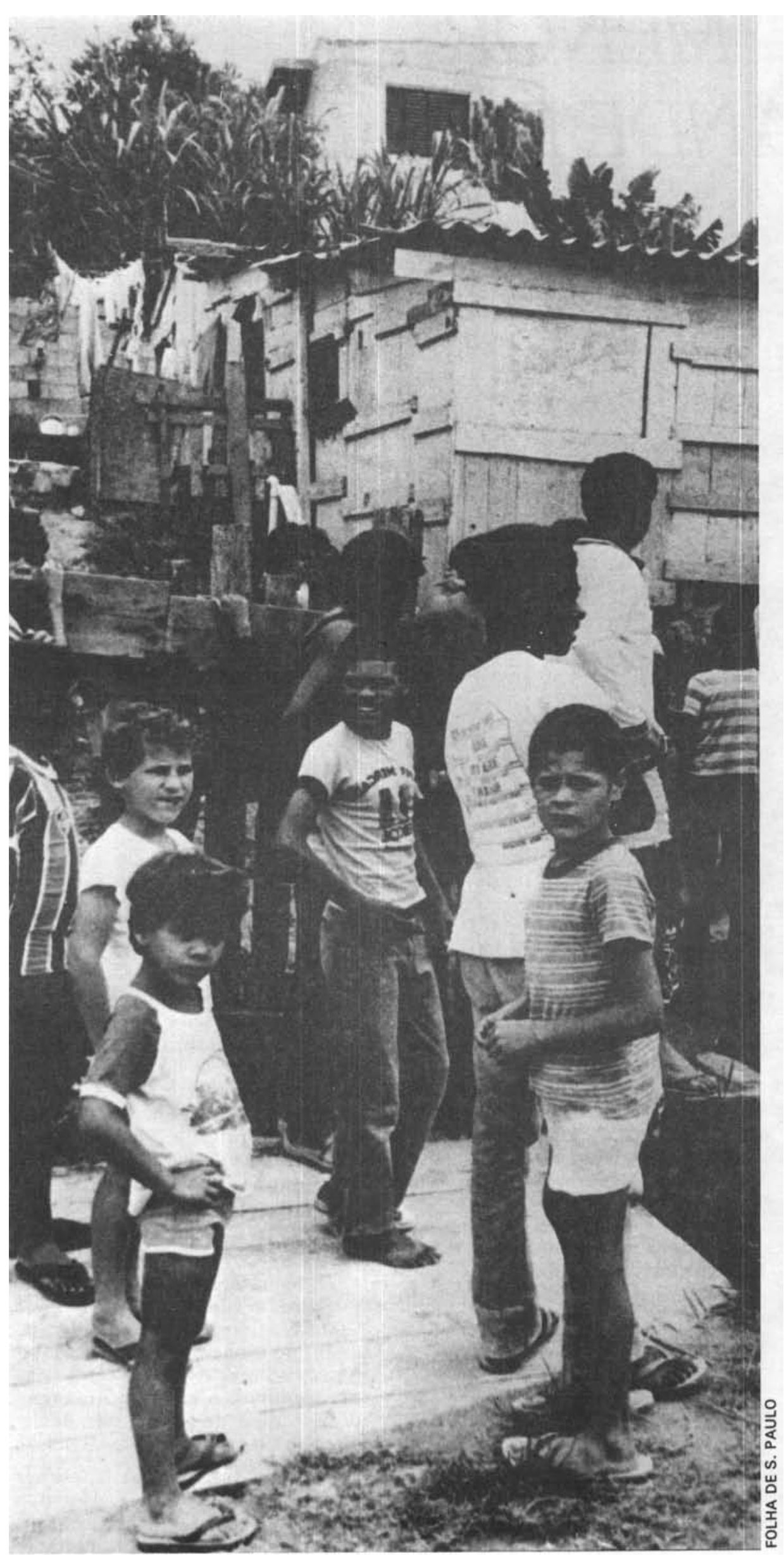

e no pensar a relaçāo com esta parcela da população, tem um alcance social diferente daquele que legitima, apenas. Porém, tanto em um, quanto em outro caso, no momento em que o falar sobre, toma o lugar do discurso próprio, estabelece-se uma relaçāo de apropriação. Parece não mais considerar-se que quando eu falo. faço-o do meu ponto de vista, ou seja, da perspectiva que me permite o lugar que ocupo na relação; esta fala nāo abarca, nāo substitui e nem é a mesma, daquele que ocupa o(s) outro(s) pólo(s) da relaçāo.

No caso da infância e, mais especificamente da infância em abandono e/ou infratora, a atribuiçăo de caráter de totalidade a um discurso parcial, configura-se numa história até certo ponto sin. gular. A apropriaçăo do discurso se dá no interior da longa e com. plexa estratégia de práticas de conservaçāo das crianças, nas formaçōes sociais capitalistas.

É característico da época mo. derna considerar a infância como uma "idade" ou "fase" da vida. Durante muito tempo, pelos altos indices de mortalidade infantil e pela estruturação política, econômica e cultural das sociedades, a criança parecia não ser reconhecida como integrante da humanidade. Se conseguisse atingir 7 anos, já era considerada adulto e passava a fazer parte da comunidade. Quando na sociedade moderna voltou-se a atenção para a criança e para a sua conservação, constituiram-se estratégias diferentes quer se tratasse da criança de família burguesa, da de família popular ou da criança delinquen. te.

Nas camadas burguesas, o cuidado com a infância se fez articulado ao processo de transforma. çāo da família numa unidade intimista, entre quatro paredes, com participantes muito claramente definidos, unidos pelos laços do afeto e do contrato social. A medicina, expandindo também seu âm. bito de ação contribuiu muito para isso, por meio da prática do médico de família: fez da mulher mãe e esposa - a extensão do braço médico e permitiu-lhe um estatuto diferente na relaçāo com o homem-marido. As práticas peda. gógicas e de higiene săo revistas e se instaura a preocupação em libe- 
rar a criança, seu corpo, seu pensamento.

Nas camadas populares, o ca. minho foi (e tem sido) diferente. As familias - aqui, de vida mais comunitária e promíscua aos olhos do Estado e da burguesia sâo alvo de regramento e controle por parte dos órgấos administrativos. $O$ esforço social em demons. trar a importância do casamento, da disciplina no trabalho, da vida caseira bem como o esforço em estabelecer padróes de higiene e organizaçăo do espaço no interior das habitaçoes, verificaram-se por meio de recursos jurídicos e técnicos. Assim, além de leis como as de salário-família, criaram. se postos de atendimento de saúde, o que permitiu a profissionais de medicina, educaçấo e psiquia. tria, ao lado de homens de Estado e da Lei, administrarem recursos e com eles, a forma de vida das classes populares. A infáncia, neste segmento da população, é, portanto, "conservada" numa es. tratégia diferente da infáncia burguesa e com o objetivo da contencáo e do controle, não mais da liberaçäo. Um projeto mais policial do que psicopedagógico, portanto; muito embora, $o$ atendimento psicológico, educativo e sanitário tenham sido o instrumento. Estiveram, entretanto, sempre inseridos numa Política Assistencial.

A crianca-infratora mereceu um terceiro tipo de atendimento $e$, assim, sua constituiçăo e conservaçáo inseriram-se numa estratégia que guarda algumas diferenças em relaçáo às anteriores. Para cuidar dos delitos infantis foram criados os Tribunais de Menor (inf́cio do século XX). E, as medidas invariavelmente tomadas eram as de reclusăo em instituicoes patronais e reeducativas ou de vigilancia em ambiente aberto. Aqui, a Justiça e a Administraçăo confluem numa assisténcia técnico-jurídico-policial. Săo os educadores, sanitaristas, assistentes sociais (profissoes que ganham grande impulso), que fazem a vigilancia e a reeducaça (na mais completa intersecça das duas práticas) e 0 fazem como uma extensăo do braço do Juiz, responsável em última instancia pela criança "indiciada".

Assim, è no interjogo de determinadas práticas sociais que se ingtitui a infancia como uma fase da vida e que se delimita uma regiâo desta infáncia, cujo atendimento e cuidado é território judiciário e administrativo. Esta regiăo é a Criança-Menor.

Nesse processo fica reconhecido o direito e o dever de assistir/ julgar/ administrar bem como o direito e o dever de ser assistido/ julgado/ administrado, como atribuiçóes de grupos distintos e complementares. A nivel do discurso fica definido o lugar de quem fala e de quem é falado, de quem refere

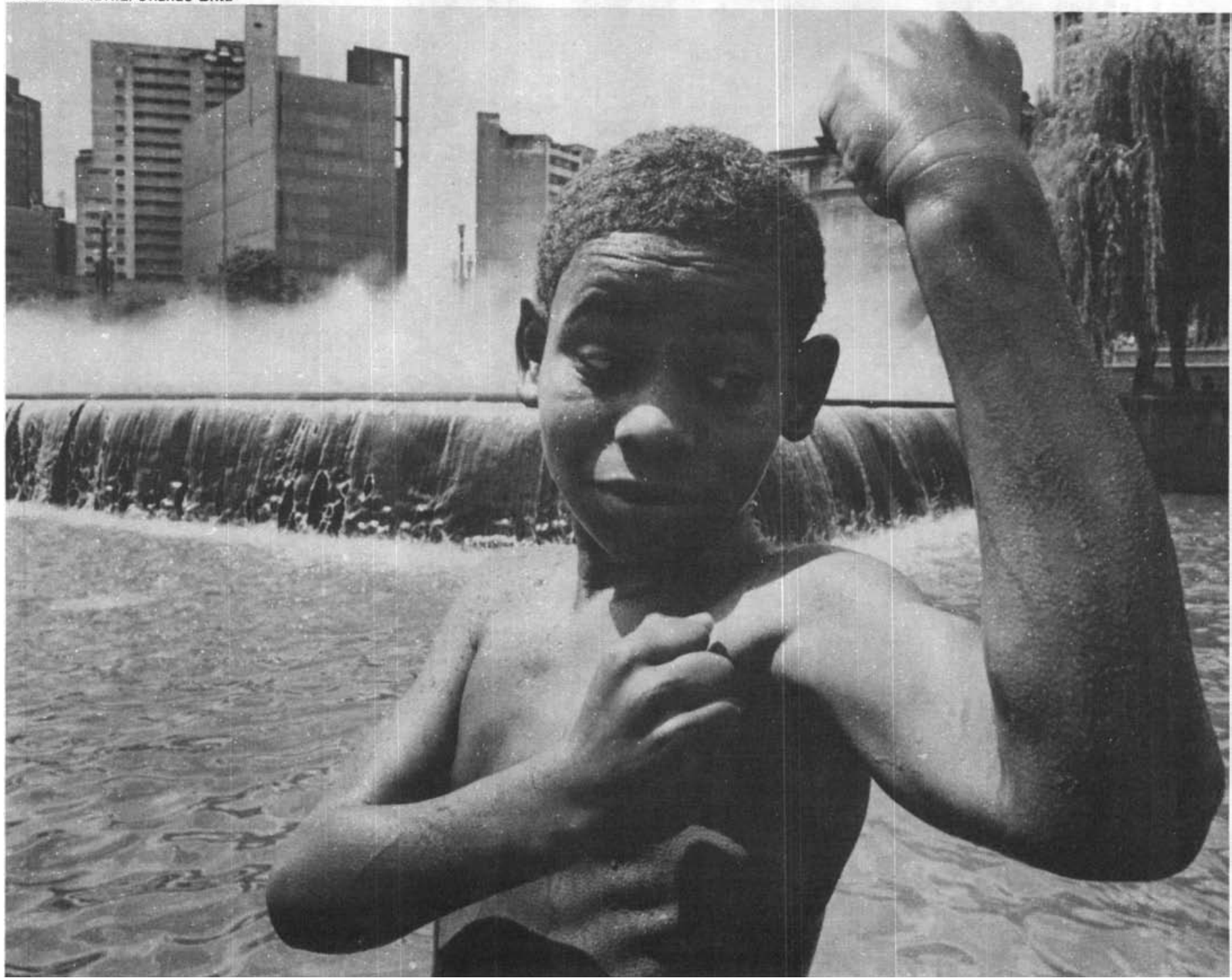


e de quem é referido; definem-se Bujeitos e objetos.

Para que nosso raciocinio nes. te texto năo se feche no determinismo linear da dominaçá, é im. portante que se denote a contradiçáo intrínseca a este conjunto de relaçoes sociais e discursivas.

Constituida na rede assistencial, a Criança-Menor é, como procuramos fundamentar, pensada como quem recebe, porque năo dispoe de recursos e, enquanto re. cebe, subordina-se e admite sua incapacidade para organizar satisfatoriamente os recursos disponiveis; seu lugar enquanto assistido $\hat{e}$, portanto, negativo: significa falta, caréncia. Contudo, pela própria natureza controladora dessa assistência, pode-se depreender uma inversao de sentido: o lugar-menor possui, contra- ditoriamente, positividade; uma positividade garantida pela infraçáo ou pela ameaça de infraçáo que representa. Quando a criança incomoda, porque mendigando nas ruas, "perambulando", assaltando ou "trombando", ela adquire na marginalidade, uma identidade, uma presença enquanto grupo social. Como marginal à sociedade constituída, legalizada, ela marca existéncia numa relação.

$\mathbf{E}$, portanto, na perturbadora categoria de participaçăo/ exclusâo que a criança das classes populares se institue Menor. E, se nosso discurso (sobre) e nossa prática (em favor de) perpetuam o esforço de exclusăo, pela prática e pelo discurso do abandono e da in. fração, a criança-menor insiste em sua participaçăo.

Vale, enfim, comentar o fato de uma vez mais - e agora, numa re. vista como esta do Conselho Federal de Psicologia - repetir-se alguém, que discursa sobre 0 "menor". Cremos, entretanto, que do interior da contradiça, este meta-discurso se justifica. Seu propósito é o de trazer uma postura, sem pretender com isto impe. dir ou anular seu contraponto que é o discurso da criança. Propöese, ainda, a contribuir para que se (re)pense nossa prática profissional enquanto psicólogo, sempre que esta prática se define na relaçăo com esta criança.

DONZELOT, J. - A policia das familias RJ: Graal, 1981.

ARIES, P. - Historia Social da criança e da familia-RJ: Zahar, 1978.

GUIRADO, M. A criança e a Febem - SP: Perspectiva, 1980.

\section{FOLHA DE S. PAULO}

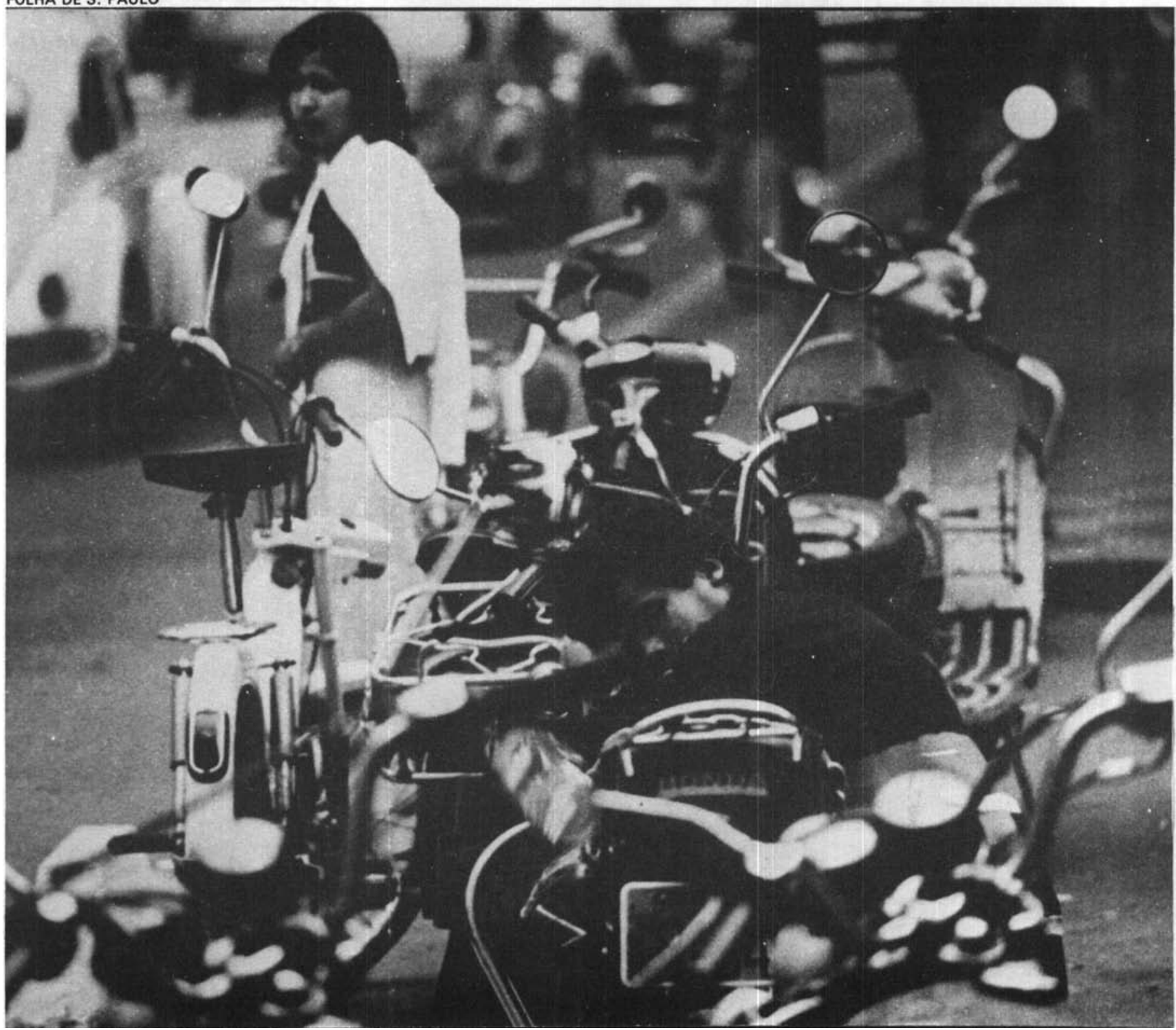

